\title{
Baseline data on the diversity and abundance of selected bird species on conventional and converting organic dairy farms
}

\author{
MARION MONDOT ${ }^{1}$, GRANT BLACKWELL ${ }^{2}$ and TANJA MAEGLI ${ }^{2}$ \\ ${ }^{1}$ Institut National Agronomique Paris-Grignon, 16 rue Claude Bernard, 75231 Paris Cedex 05 \\ ${ }^{2}$ Center for Study of Agriculture, Food and Environment, PO Box 56, \\ The University of Otago, Dunedin, New Zealand \\ grant.blackwell@stonebow.otago.ac.nz
}

\begin{abstract}
While it has been shown that bird species can benefit from organic farm management internationally, there is little information on birds in production landscapes in $\mathrm{NZ}$. In this paper we apply spatial analysis techniques to compare the spatial distribution and habitat use of birds on selected North Island dairy farms, half of which are undergoing a 3-year organic conversion process and half of which are remaining under conventional management. There were significantly more skylarks recorded on conventionally managed farms. Overall however, there were few differences in overall bird abundance or diversity between the two management systems. The comparable use of woody vegetation and open pasture may reflect similar proportions and composition of these on the study farms. Once fully converted, organic dairy production systems may offer benefits for some bird species, although the composition and management of the farm and surrounding landscape are probably also key factors for bird numbers and diversity.
\end{abstract}

Keywords: birds, dairy farming, landscape composition, organic conversion, pasture composition

\section{Introduction}

Biodiversity is integral to the functioning of agroecosystems. Biodiverse ecosystems provide services essential to commodity production, such as nitrogen fixation, decomposition, pollination, and pest control (Matson et al. 1997), and more biodiverse systems are believed to have a greater capacity to absorb and recover from perturbation, termed resilience (Fischer et al. 2006). Organically managed ${ }^{1}$ farms have been shown to support a greater diversity or abundance of plant species (Hald 1999; Moreby et al. 1994; Hyvonen et al. 2003), insect species (Dritschilo \& Wanner 1980; Moreby et al. 1994; Letourneau \& Goldstein 2001), birds (Wilson et al. 1997; Chamberlain et al. 1999; Freemark \& Kirk 2001) and mammals (Brown 1999; Wickramasinghe et al. 2003) than conventionally managed farms. Thus organic farming techniques are hypothesised to lead to more resilient agricultural ecosystems and more sustainable farming practices.

Pasture composition, biomass and sward quality are likely to be the first vegetation features to change on dairy farms undergoing organic conversion (for examples see Hole et al. 2005), with subsequent changes in the behaviour and/or abundance of insects, bird and mammal species associated with this habitat. As the diversity and abundance of bird species is potentially indicative of cascading changes in biodiversity across trophic levels of the agroecosystem, birds are seen as good indicators of wider system biodiversity and resilience (Furness et al. 1993).

This study is part of the Agriculture Research Group on Sustainability project (www.ARGOS.org.nz) investigating alternative pathways to more sustainable agriculture in New Zealand. Within the dairy sector, the wider ARGOS project is investigating the impacts and consequences of conversion to organic management on the economic, social and environmental performance of the farm operation. The organic conversion farms are currently 2 years into the 3 -year conversion process, so our hypothesis is that there is no difference in the landscape composition and degree of wood vegetation present on organic conversion or conventional dairy farms. However, we also predict that changes in pasture composition or quality may already be occurring, so we expect to see differences in the proportional use of pasture habitats by key bird species and a corresponding increase in their abundance in pasture.

In this study we first compare the landscape composition of organic conversion and conventional farms, before comparing the bird abundance and diversity on the farms. We then focus specifically on the use of open pasture by selected key bird species that may show rapid behavioural response to changes in pasture composition and quality.

\section{Methods}

We employed a replicated BACI (Before-After, Control-

\footnotetext{
${ }^{1}$ We define the term "organic management" as a form of agriculture which avoids or largely excludes the use of synthetic fertilizers and pesticides, plant growth regulators, and livestock feed additives. We follow Chamberlain et al. (1999) and define "conventional management" as farms where the land use and crop management are within the normal range of variation for the local area, and can include the use of synthetic chemicals.
} 
Figure 1 Locations of the dairy farms included in the study. Each circle represents a cluster of farms, with each cluster containing one Organic Conversion and one Conventional farm.

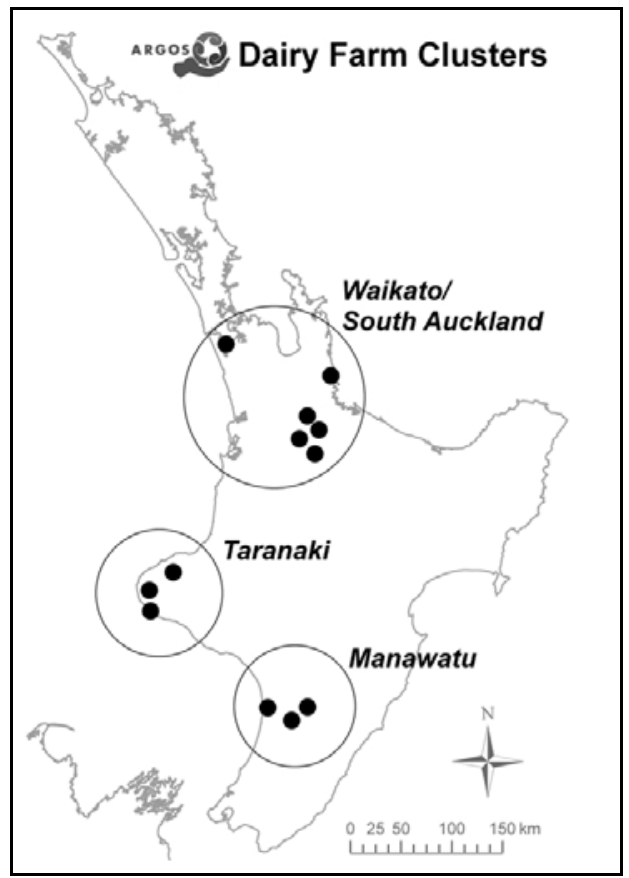

Impact) design in the dairy farms to investigate the impacts of organic conversion. There are 24 farms in the current study (Fig. 1), arranged in 12 geographically spaced, matched pairs (clusters). The clusters are located in the Waikato/South Auckland (six clusters), Taranaki (three clusters) and the Manawatu (three clusters). The two farms in a cluster were closely matched for factors such as altitude, size and rainfall. Each cluster consisted of one farm undergoing organic conversion, and one farm maintaining conventional management; thus we employed a randomised block design with management system as the fixed effect and cluster as the random effect. All farms in the study were in year 2 or 3 of the organic conversion process.

\section{Bird survey techniques}

Bird communities were surveyed on all the study farms in January 2007 using randomly located line-transects of $250 \mathrm{~m}$ length. All transects on a single farm were surveyed on the same day, and each farm was visited once during the survey. Observers walked at a constant pace $(2-3 \mathrm{~km} / \mathrm{h})$ along the transect recording all seen/ heard birds. For each detection the observer recorded the species and its direction and distance (using a Bushnell Yardage Pro ${ }^{\circledR}$ laser range finder (Bushnell Performance Optics, Overland Park, Kansas) from the transect line. The observer also noted down their own location as indicated by a Garmin eTrex GPS unit. In the rare cases where groups of birds ( $>3$ birds $-10 \%$ of the records) were seen, the number of birds in the group was estimated and the distance to the centre of the group was recorded. For more details of the survey technique see Blackwell et al. (2005).

We focused on bird species that are known to forage or nest in open habitats (Heather \& Robertson 1996) and which may show behavioural or numerical responses to organic conversion. The selected species included: two woodland species, blackbird (Turdus merula) and song thrush (T. philomelos); three omnivorous species known to forage in pasture habitats, goldfinch (Carduelis carduelis), greenfinch (C. chloris), and yellowhammer (Emberiza citrinella); an open habitat species, skylark

Table 1 Land cover classes used in the current study.

\begin{tabular}{ll}
\hline Land cover classes & Baseline land cover classes \\
\hline Open Paddock & Pasture, fenced waterways \\
Woody Vegetation & Woody vegetation patches, forestry, shelterbelts, scrubs and gulley vegetation \\
Other & Utility area, house \& garden area, races, wetland area, unknown, other \\
\hline
\end{tabular}


(Alauda arvensis); and two native insectivorous passerines that are relatively common on farms and may show foraging responses to organic conversion, fantail (Rhipidura fuliginosa) and grey warbler (Gerygone ignata).

\section{Land cover survey}

Baseline ecological surveys were undertaken on each farm during October and November 2005. The land cover was mapped in detail resulting in a land cover features class that is part of an extensive ARGOS GIS database (ArcGIS v9.2). To enable comparison with the habitat types of the bird survey, the detailed land cover classes have been summarised into three main categories (Table 1).

The structural patterns of the land cover classes were analysed in ArcGIS with the extension V-Late (vectorbased landscape analysis tools extension: Lang \& Tiede 2003). We selected measures that describe a range of landscape patterns, classified into two categories (McGarigal \& Marks 1995). Patch-scale metrics (i.e. attributes of the individual woody vegetation patch) included: the average distance between neighbouring patches (Nearest Neighbour - NN); and two measures of patch shape, the Shape Index (SI) and the Fractal Dimension (FRAC). Class-scale metrics (i.e. mean of the attributes per farm) included: the average number of woody patches per farm (Number of Patches - NP), the Mean Patch Size (MPS) and the Mean Patch Size Standard Deviation (MPSS).

Locations of individual birds detected in the bird survey were entered into the GIS database as a data layer, and were then used to analyse the spatial distribution and habitat use (open pasture or woody vegetation) of birds across the farms.

\section{Statistical analysis}

Differences in landscape composition and structure, and bird abundance and species richness, between conventional and organic conversion management systems were tested using a randomised block design and a nested analysis of variance. All analyses were conducted in Genstat Version 9 (VSN International Ltd). Management system was nested within cluster, with the two management systems (conventional and organic conversion) present once within each of the 12 clusters. Data were $\log _{10}(\mathrm{x}+1)$ transformed and were analysed assuming a normal error structure and identity link function. Data for skylarks could not be normalised, and consequently skylark abundance data were analysed using a Generalised linear model with a Poisson error term and $\log$ link function.

Proportional habitat use was analysed using Logistic regression with a binomial error distribution and logit link. Individual models, built for each of the focal species, specified the proportion of total sightings that were recorded in open habitats as the response, and included geographical cluster and management system as the explanatory variables. Genstat controls for the effect of any previously entered variables and ignores any subsequent variables for each individual test (Payne 2006), and reports the deviance ratio and probability from a $\chi^{2}$ approximation of the deviance ratio distribution. For the current study with only two factors in the model,

Table 2 Patch (within-farm) metrics for the dairy farms in the current study. Shown are the average values $( \pm$ s.e.) per farm for the woody patch area, the distance to the nearest woody patch (NN), shape index (SI), and the fractal dimension (FRAC).

\begin{tabular}{lcccc}
\hline Patch metric & $\begin{array}{c}\text { Conventional } \\
\text { Mean } \pm \text { s.e. }\end{array}$ & $\begin{array}{c}\text { Organic conversion } \\
\text { Mean } \pm \text { s.e. }\end{array}$ & $\begin{array}{c}\text { Test of Panel } \\
\text { effect }\end{array}$ & $\mathrm{P}$ \\
\hline $\mathrm{NN}(\mathrm{m})$ & $55.3 \pm 6.0$ & $46.6 \pm 5.9$ & $\mathrm{~F}_{1,10}=1.96$ & 0.192 \\
$\mathrm{SI}$ & $2.5 \pm 0.1$ & $2.7 \pm 0.1$ & $\mathrm{~F}_{1,404}=0.001$ & 0.956 \\
FRAC & $1.60 \pm 0.02$ & $1.74 \pm 0.05$ & $\mathrm{~F}_{1,399}=0.59$ & 0.443 \\
\hline
\end{tabular}

Table 3 Class (farm-scale) metrics for the dairy farms in the current study. Shown are the average values ( \pm s.e.) per farm for the number of woody patches, total woody area, standard deviation of the average patch size, and the proportion of the farm covered by woody vegetation.

\begin{tabular}{lcccc}
\hline Class metric & $\begin{array}{c}\text { Conventional } \\
\text { Mean } \pm \text { s.e. }\end{array}$ & $\begin{array}{c}\text { Organic conversion } \\
\text { Mean } \pm \text { s.e. }\end{array}$ & $\begin{array}{c}\text { Significance } \\
\text { test }\end{array}$ & $\mathrm{P}$ \\
\hline NP & $16.7 \pm 2.3$ & $19.6 \pm 2.9$ & $\mathrm{~F}_{1,10}=1.13$ & 0.313 \\
Total woody area (ha) & $5.8 \pm 1.1$ & $15.8 \pm 5.8$ & $\mathrm{~F}_{1,10}=1.42$ & 0.260 \\
MPS (ha) & $0.37 \pm 0.59$ & $0.96 \pm 0.37$ & $\mathrm{~F}_{1,10}=0.19$ & 0.674 \\
MPPS & $0.5 \pm 0.1$ & $1.8 \pm 0.9$ & $\mathrm{~F}_{1,10}=0.97$ & 0.347 \\
Woody vegetation & $7.2 \pm 1.5$ & $15.9 \pm 4.6$ & $\mathrm{~F}_{1,10}=2.58$ & 0.140 \\
$\quad$ (\% of total area) & & & & \\
\hline
\end{tabular}


Figure 2 The average abundance of birds recorded (birds/100 $\mathrm{m}$ of transect) in open habitats, woody habitats and in total (both open and woody habitats combined) on 12 matched-pairs of dairy farms. In each pair, one farm is undergoing organic conversion while one is continuing with conventional farm management. For an explanation of the survey design see the methods section. Error bars signify one standard error.

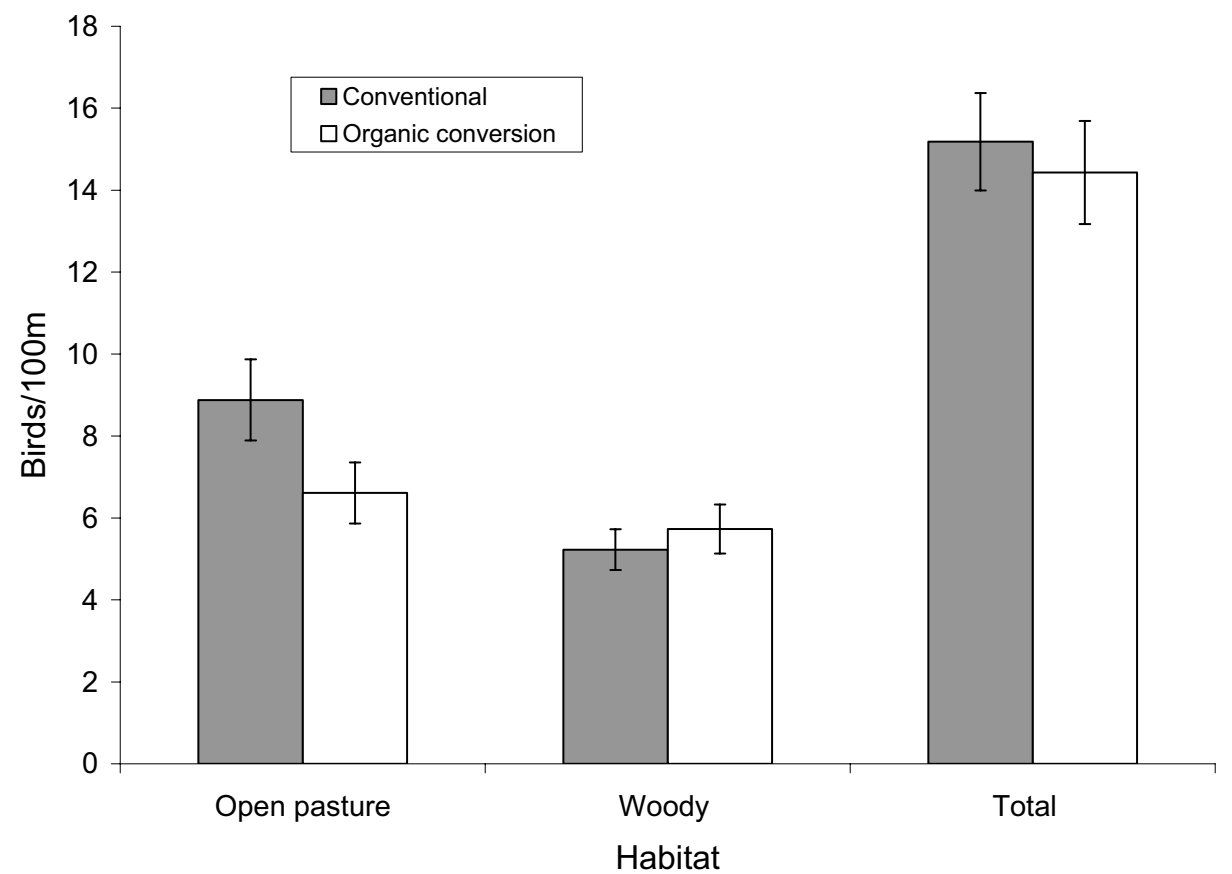

Figure 3 The average species richness (species recorded/100 m of transect) in open habitats, woody habitats and in total (both open and woody habitats combined) on 12 matched-pairs of dairy farms. Error bars signify one standard error.

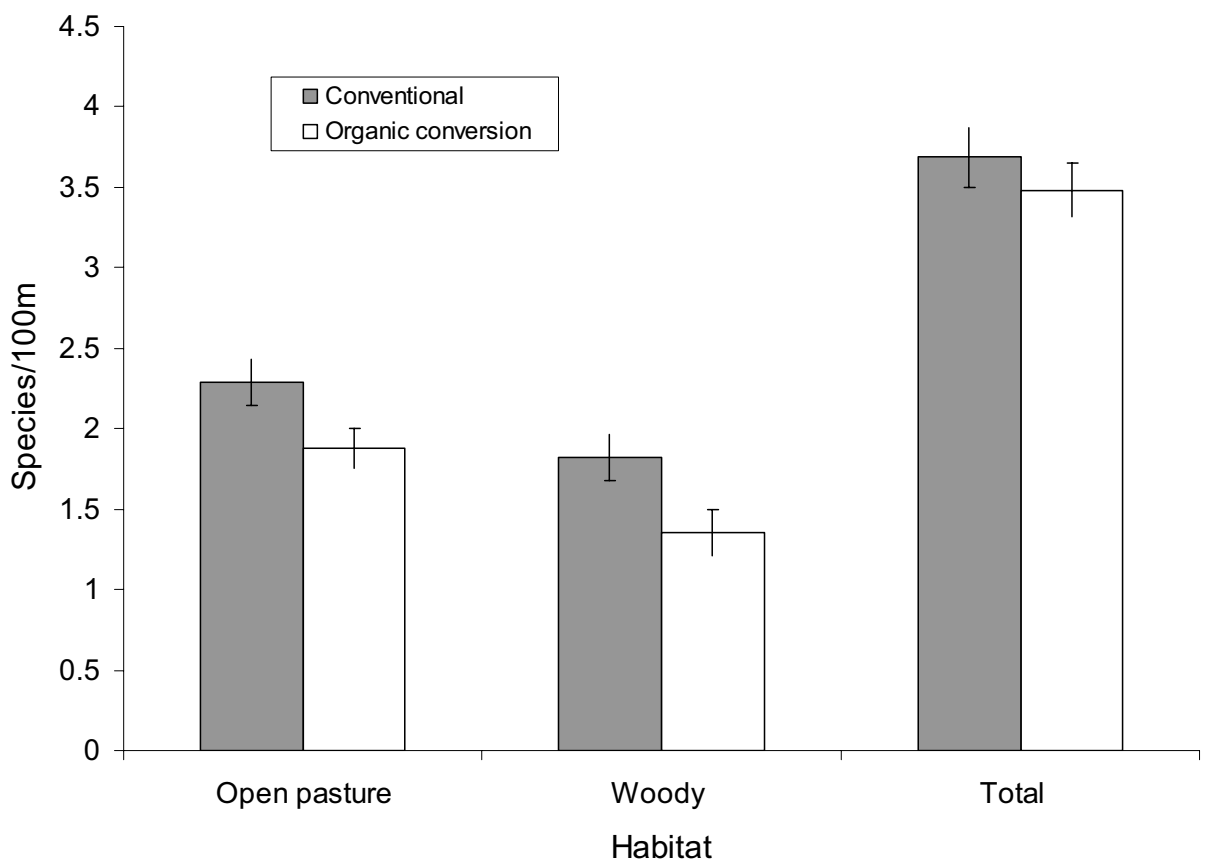


Table 4 Predicted average proportional use of open habitats ( \pm standard error) on Conventional and Organic conversion dairy farms by selected species in the current study. Predictions are derived from General Linear Models and are controlled for any differences between geographical clusters. Also shown are the deviance ratio from the full model (Constant + Cluster + Panel), and the deviance ratio for the farm management (Conventional or Organic conversion) effect controlled for any geographical cluster effect. $P$ values are from $\chi^{2}$ approximations of the deviance ratio distributions.

\begin{tabular}{lcccccc}
\hline Species & Conventional & $\begin{array}{c}\text { Converting } \\
\text { organic }\end{array}$ & Full model & $P$ & $\begin{array}{c}\text { Farm } \\
\text { management } \\
\text { effect }\end{array}$ & $P$ \\
\hline Blackbird & $0.23 \pm 0.06$ & $0.39 \pm 0.05$ & $\mathrm{~F}_{12,59}=2.11$ & 0.013 & $\mathrm{~F}_{1,59}=3.26$ & 0.071 \\
Thrush & $0.50 \pm 0.08$ & $0.71 \pm 0.07$ & $\mathrm{~F}_{12,23}=1.99$ & 0.021 & $\mathrm{~F}_{12,23}=2.92$ & 0.088 \\
Skylark & $0.94 \pm 0.01$ & $0.84 \pm 0.03$ & $\mathrm{~F}_{12,118}=3.45$ & $<0.001$ & $\mathrm{~F}_{1,118}=15.83$ & $<0.001$ \\
Goldfinch & $0.67 \pm 0.02$ & $0.72 \pm 0.02$ & $\mathrm{~F}_{12,117}=9.30$ & $<0.001$ & $\mathrm{~F}_{1,117}=1.63$ & 0.201 \\
Greenfinch & $0.47 \pm 0.04$ & $0.41 \pm 0.03$ & $\mathrm{~F}_{12,118}=2.94$ & $<0.001$ & $\mathrm{~F}_{1,118}=1.21$ & 0.271 \\
Yellowhammer & $0.55 \pm 0.06$ & $0.46 \pm 0.04$ & $\mathrm{~F}_{12,86}=3.33$ & $<0.001$ & $\mathrm{~F}_{1,86}=1.87$ & 0.280 \\
Fantail & $0.65 \pm 0.03$ & $0.11 \pm 0.04$ & $\mathrm{~F}_{10,40}=2.37$ & 0.009 & $\mathrm{~F}_{1,40}=0.74$ & 0.389 \\
Grey warbler & $0.03 \pm 0.14$ & $0.00 \pm 0.00$ & $\mathrm{~F}_{9,30}=0.58$ & 0.811 & $\mathrm{~F}_{1,30}=0.51$ & 0.477 \\
All species & $0.53 \pm 0.02$ & $0.53 \pm 0.02$ & $\mathrm{~F}_{12,163}=11.81$ & $<0.001$ & $\mathrm{~F}_{1,163}=0.02$ & 0.864 \\
\hline
\end{tabular}

the deviance ratios are equivalent tests of the Panel effect to the t-tests of parameter estimates (Payne 2006).

\section{Results}

\section{Landscape composition of study farms}

All of the class- and patch-scale landscape metrics were highly variable between the geographic clusters, although once this variation was controlled for there were no significant differences between the management systems, either for the patch-scale metrics (Table 2), or the classscale metrics (Table 3).

\section{Bird abundance}

The abundance of birds in open and woody habitats, and the total abundance for birds on the transects, was very similar between the conventional and 2-3 year old organic conversion dairy farms. The average number of birds/ $100 \mathrm{~m}$ in woody habitats was higher on organic conversion farms, while the average abundance in open habitats and in total was higher on conventional farms (Fig. 2). However, once the differences between the geographical clusters were controlled for, these differences between management systems were not significant (open habitats: $\mathrm{F}_{1,10}=2.33, \mathrm{P}>0.05$; woody habitats: $\mathrm{F}_{1,10}=0.12, \mathrm{P}>0.05$; all habitats: $\mathrm{F}_{1,10}=1.0$, $\mathrm{P}>0.05)$. Skylarks were the only species that differed significantly in abundance between the management systems in any of the habitats, with significantly more skylarks in open habitats on conventional farms $\left(\mathrm{F}_{1,173}=\right.$ 44.09, $\mathrm{P}<0.001$ ).

\section{Species richness}

The number of bird species in open and woody habitats, and the total species richness for birds on the transects, was very similar between management systems. In all three cases, the species richness was higher on conventional farms (Fig. 3), although these differences between management systems were not significant (open habitats: $\mathrm{F}_{1,10}=3.03, \mathrm{P}>0.05$; woody habitats: $\mathrm{F}_{1,10}=$ $0.42, \mathrm{P}>0.05$; all habitats: $\mathrm{F}_{1,10}=2.42, \mathrm{P}>0.05-$ all data $\log _{10}+1$ transformed).

\section{Habitat use}

For all species except the grey warbler, the proportional use of open habitats was significantly different between the clusters (Table 4). Skylarks were the only species to show any differences in habitat use between the two management systems, and were recorded significantly more often in open habitats on conventional than on organic conversion farms. An example of the distribution of some of the focal species recorded on one of the farms is shown in Figure 4. For this farm, all the skylarks were recorded in open habitats, and all but one of the grey warbler records were in woody vegetation. Goldfinch were recorded both in woody habitats and open pasture.

\section{Discussion}

This baseline survey found little evidence of differences in either overall bird diversity or the abundance and habitat use of individual species between organic conversion and conventionally managed farms. We did, however, find significantly higher abundances of skylarks and greater proportional use of open pasture on conventionally managed farms. International studies have demonstrated higher summer and winter densities of skylarks on organic than on conventional farms, with these differences related to greater diversity of field types and food availability on organic farms (Chamberlain et al. 1999; Wilson et al. 1997). Similar to our findings, a study of skylark breeding success in Canterbury New Zealand found that skylark densities were lower in organically managed pastures than on conventionally managed ones (Thomsen 2002). The author attributed the higher densities in conventional fields to smaller 
Figure 4 Example of the bird distribution on one farm. Shown are the land cover classes and the distribution of three of the selected key species, goldfinch, grey warbler and skylark.

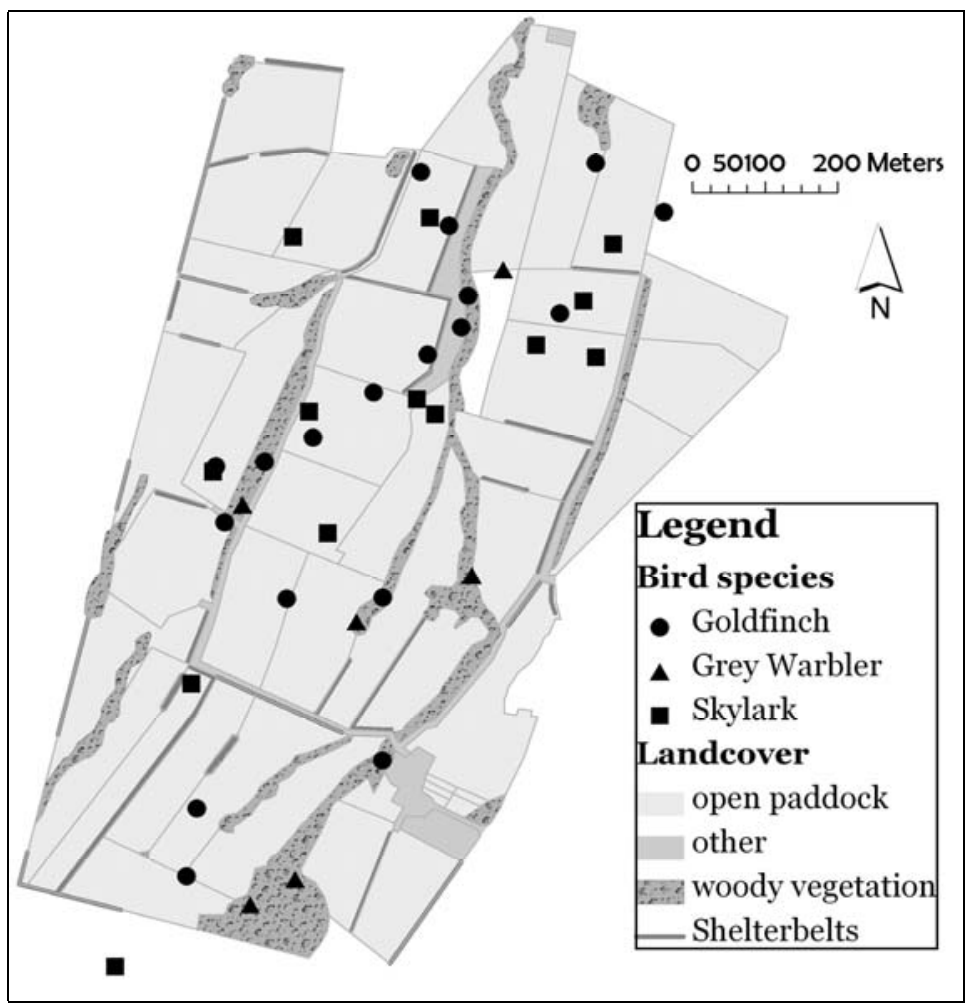

paddock areas with more extensive woody vegetation margins under organic management. Such fields have been previously shown to be generally avoided by skylarks (Donald et al. 2001; Gillings 2001). The average paddock size was similar on organic conversion and conventional farms in our study (median paddock size: organic conversion $=1.68$ ha, conventional $=1.74$ ), and although vegetation blocks tended to be at higher density on organic conversion farms, this was not significantly different between the panels. The only data we have on food resources in pasture come from soil surveys in 2005, which showed that earthworm biomass was higher on conventional farms than on organic farms. Earthworms are not a major, if any, part of the skylark diet (Heather \& Robertson 1996; Donald et al. 2001), so this difference is unlikely to be driving differences in skylark abundance between organic conversion and conventional farms. We have no data on predation pressure on our study farms or the pasture composition and quality on organic conversion or conventional farms. One New Zealand study found no major differences in pasture composition in an organically managed field during the first 3 years of organic conversion (Kelly et al. 2005), and it is possible the same situation applies in our study.

We have compared the landscape composition and aspects of the bird communities present on New Zealand dairy farms undertaking two divergent management systems. Our organic farms are currently undergoing the conversion process, and are not yet expected to show any significant management related differences in woody vegetation characteristics, pasture composition, farm structure (e.g. paddock size) or biodiversity values. We do not know if organic and conventionally managed dairy farms will ultimately support different bird communities. However, the fact that no significant differences were found at this stage highlights the strength of the BACI approach and provides a robust basis for the ARGOS project's ongoing investigations of the prevalence or extent of management related temporal changes on New Zealand dairy farms.

\section{ACKNOWLEDGEMENTS}

The authors would like to thank J. Lurling, J. Lach, S. Mcguire and N. Percy for data collection, and all the participating farmers for allowing us access to their properties. The project was funded by the New Zealand Foundation for Research, Science and Technology and a New Zealand Ministry of Agriculture and Forestry Sustainable Farming Fund grant. 


\section{REFERENCES}

Blackwell, G.; Rate, S.; Moller, H. 2005. ARGOS biodiversity surveys on Kiwifruit orchards and Sheep/ beef farms in summer 2004/05: rationale, focal taxa and methodology. Agriculture Research Group on Sustainability. Report 05/05. Dunedin.

Brown, R.W. 1999. Margin/field interfaces and small mammals. Aspects of Applied Biology 54: 203-210.

Chamberlain, D.E.; Wilson, J.D.; Fuller, R.J. 1999. A comparison of bird populations on organic and conventional farm systems in southern Britain. Biological Conservation 88: 307-320.

Donald, P.F.; Buckingham, D.L.; Moorcroft, D.; Muirhead, L.B.; Evans, A.D.; Kirby, W.B. 2001. Habitat use and diet of skylarks Alauda arvensis wintering on lowland farmland in southern Britain. Journal of Applied Ecology 38: 536-547.

Dritschilo, W.; Wanner, D. 1980. Ground beetle abundance in organic and conventional corn fields. Environmental Entomology 9: 629-631.

Fischer, J.; Lindenmayer, D.B.; Manning, A.D. 2006. Biodiversity, ecosystem function, and resilience: ten guiding principles for commodity production landscapes. Frontiers in Ecology and the Environment 4: 80-86.

Freemark, K.E.; Kirk, D.A. 2001. Birds on organic and conventional farms in Ontario: partitioning effects of habitat and practices on species composition and abundance. Biological Conservation 101: 337-350.

Furness, R.W.; Greenwood, J.J.D.; Jarvis, P.J. 1993. Can birds be used to monitor the environment? pp. 135. In: Birds as monitors of environmental change. Eds. Furness, R.W. and Greenwood, J.J., Chapman and Hall, London.

Gillings, S. 2001. Factors affecting the distribution of skylarks Alauda arvensis wintering in Britain and Ireland during the early 1980s. pp. 115-128. In: The ecology and conservation of skylarks Alauda arvensis. Eds. Donald, P.; Vickery, J.A., Royal Society for the Protection of Birds, Sandy.

Hald, A.B. 1999. Weed vegetation (wild flora) of long established organic versus conventional cereal fields in Denmark. Annals of Applied Biology 134: 307-314.

Heather, B.D.; Robertson, H.A. 1996. The Field Guide to the Birds of New Zealand. Viking.Auckland. 440 pp.

Hole, D.G.; Perkins, A.J.; Wilson, J.D.; Alexander, I.H.; Grice, P.V.; Evans, A.D. 2005. Does organic farming benefit biodiversity? Biological Conservation 122: 113-130.
Hyvonen, T.; Ketoja, E.; Salonen, J.; Jalli, H.; Tiainen, J. 2003. Weed species diversity and community composition in organic and conventional cropping of spring cereals. Agriculture, Ecosystems and Environment 97: 131-149.

Kelly, T.; Butcher, N.; Harrington, K.; Holmes, C.; Horne, D.; Kemp, P.; Palmer, A.; Quinn, A.; Shadbolt, N.; Thatcher, A. 2005. Organic-conventional dairy systems trial in New Zealand: four years' results. pp. 268-271. In: Proceedings of the 1st Scientific Conference of the International Society of Organic Agriculture Research: Researching Sustainable Systems.

Lang, S.; Tiede, D. 2003. vLATE Extension für ArcGIS - vektorbasiertes Tool zur quantitativen Landschaftsstrukturanalyse. Innsbruck. http:// www.geo.sbg.ac.at/larg/.

Letourneau, D.K.; Goldstein, B. 2001. Pest damage and arthropod community structure in organic vs. conventional tomato production in California. Journal of Applied Ecology 38: 557-570.

Matson, P.A.; Parton, W.J.; Power, A.B.; Swift, M.J. 1997. Agricultural intensification and ecosystem properties. Science 277: 504-509.

McGarigal, K.; Marks, B. 1995. Fragstats: spatial pattern analysis program for quantifying landscape structure. US Forest Service General Technical Report PNWGTR-351. Corvallis.

Moreby, S.J.; Aebischer, N.J.; Souhway, S.E.; Sotherton, N.W. 1994. A comparison of the flora and arthropod fauna of organically and conventionally grown winter wheat in southern England. Annals of Applied Biology 125: 13-27.

Payne, R.W. (ed.). 2006. The guide to Genstat Version 9. Part 2: Statistics. Lawes Agricultural Trust. 1058 pp.

Thomsen, S. 2002. The ecology of the skylark Alauda arvensis L. on the Canterbury Plains, New Zealand. $\mathrm{PhD}$ Thesis. Lincoln University.

Wickramasinghe, L.P.; Harris, S.; Jones, G.; Vaughan, N. 2003. Bat activity and species richness on organic and conventional farms: impact of agricultural intensification. Journal of Applied Ecology 40: 984993.

Wilson, J.D.; Evans, J.; Browne, S.J.; King, J.R. 1997. Territory distribution and breeding success of skylarks Alauda arvensis on organic and intensive farmland in southern England. Journal of Animal Ecology 34: 14621478 . 